Compreendendo as InOvações EMpreendidas nOS Sistemas de Operações de Serviços por meio do Método PCN Analysis: UM estudo de múltiplos CASOS EM SERVIÇOS DE ATENDIMENTO AO CIDADÃO

\author{
Understanding the Innovations Implemented in the Service \\ Operations Systems Through the method PCN Analysis: a \\ multiple case study on customer service assistance
}

\title{
Leila Scanfone
}

Doutoranda em Administração pela Universidade Federal de Minas Gerais. Belo Horizonte, MG. Brasil. E-mail: scanfone@uol.com.br

Noel Torres Júnior

Professor Adjunto da Universidade Federal de Minas Gerais. Belo Horizonte, MG. Brasil. E-mail: noelface@gmail.com

\section{Resumo}

Diante do forte crescimento e competição no setor de serviços, a demanda por maior efetividade nas organizações deste setor se faz cada vez mais presente. Nesse contexto, novos serviços devem ser desenvolvidos por meio de um projeto de serviço que possibilite processos mais eficientes e que entregue uma proposta adequada de valor ao cliente. Posto isto, o presente trabalho utiliza o diagrama ProcessChain-Network (PCN) e o seu método de análise, para melhor compreender as características das inovações empreendidas nos sistemas de operações e suas implicações no processo de oferta de valor, em três projetos de serviços de atendimento ao cidadão, ofertados pela Polícia Militar de Minas Gerais. Os dados coletados em campo, por meio de entrevistas, documentos e observação direta, possibilitaram a construção do diagrama PCN e a análise do mesmo para cada serviço. Os resultados apontaram que a aplicação do método PCN Analysis é eficaz no entendimento das diferenças e similaridades existentes nas inovações empreendidas nos projetos de serviços estudados.

Palavras-chave: Projeto de Serviços. PCN Analysis. Inovação em Serviços. Oferta de Valor.

\section{Abstract}

In the face of the strong growth and competition in the service sector, the demand for higher effectiveness in organizations of this area becomes increasingly present. In this context, new services should be developed through a service project that enables more efficient processes and to deliver an appropriate proposal of customer value. Hereupon, this study uses the ProcessChain-Network (PCN) diagram and its method of analysis to understand better the characteristics of innovations implemented in operations systems and their implications for the value proposition process on three services projects of customer service assistance offered by the Military Police of Minas Gerais. The data collected in the field through interviews, documents, and direct observations enabled the construction of the PCN diagram, and its analyze for each service. The results showed that the application of the method PCN Analysis is effective in understanding the differences and similarities in the innovations implemented in the service projects studied.

Keywords: Service Project. PCN Analysis. Innovation in Service. Offer Value. 


\section{INTRODUÇÃO}

Nas últimas décadas, a expansão do setor de serviços na economia global trouxe a necessidade de uma melhor gestão dos mesmos (GIANNAKIS, 2011). Nesse contexto, a demanda por maior efetividade exige das organizações a capacidade de realizar inovações em seus processos que proporcionem soluções adequadas para cada cliente e melhores resultados para ambas as partes. Para tanto, o projeto adequado de serviço tornou-se fundamental para a consecução deste objetivo. Haja vista que tal projeto possibilita o alcance da eficácia desejada pela organização, por meio da concepção e construção de processos adequados $e$ eficientes que entreguem a proposta de valor esperada pelo cliente (SALVENDY; KARWOWSKI, 2010).

Além disso, os gestores das organizações têm percebido que o projeto de serviço precisa estar ancorado no nível estratégico do negócio, uma vez que é um elemento essencial para a oferta de novos serviços ou a melhoria dos atuais (MAGER; SUNG, 2011), além de impactar nos custos de sua prestação e na própria satisfação do cliente.

Nesse cenário, o foco principal do projeto de serviço não deve ser a explicitação dos aspectos tangíveis, mas da proposta de valor ofertada (Burkhardt, 1995 apud MAGER; SUNG, 2011, p. 1), já que a proposição de valor é a finalidade de um sistema de serviço (GRÖNROOS, 2008; SAMPSON, 2012).

Nessa direção, a existência de elementos tangíveis como qualidade e uma estrutura física adequada são importantes para a oferta do serviço, no entanto, é o seu projeto que proporcionará a entrega apropriada para o cliente, uma vez que este "[...] abrange o desenho de toda experiência de um serviço, como também o projeto do processo e da estratégia para a prestação do mesmo" (MORITZ, 2005, p. 39).

Todavia, ainda que existam diversas ferramentas de apoio à análise de processos, há uma lacuna no que se refere aos métodos e técnicas a serem utilizados na realização do desenvolvimento e desenho em serviços, especialmente, quando se analisa processos de serviços inseridos em sistemas que envolvam diversas entidades. Com o objetivo de lidar com essa lacuna, criou-se o diagrama Process-Chain-Network (PCN). Esse diagrama documenta as interações existentes entre as etapas presentes nos diversos domínios de processos que lidam com várias entidades em um sistema de serviço, considerando os distintos papéis que cada entidade exerce no processo (SAMPSON, 2014).

Posto isso, o presente trabalho utiliza o diagrama Process-Chain-Network (PCN) e o seu método de análise para compreender o projeto de serviço empreendido pela organização, de tal modo que possibilite a identificação das inovações empreendidas nos seus sistemas de operações e suas implicações no processo de oferta de valor. Essa análise é conduzida em três serviços de atendimento ao cidadão, ofertados pela Polícia Militar de Minas Gerais.

Importante ressaltar que este estudo faz uma maior elucidação das diversas formas de oferta de valor ressaltadas pela literatura de gestão de serviços. Além disso, o trabalho também aponta algumas questões estruturais pertinentes ao projeto de serviço. Nesse rumo, o estudo busca refletir sobre a teoria existente por meio da análise de casos de serviços implementados por uma grande organização.

Para tanto, o artigo começa abordando a questão da inovação em processos de serviços, os modelos de oferta de valor e o método PCN Analysis. Na sequência, encontram-se os procedimentos metodológicos utilizados para atingir o objetivo do presente estudo. Os achados da pesquisa são, em seguida, apresentados e discutidos, por meio de um quadro comparativo. Por fim, algumas limitações e sugestões de futuras pesquisas são apresentadas.

\section{Referencial Teórico}

Nesta seção são expostos os subsídios teóricos que nortearam o presente trabalho e possibilitaram o alcance do objetivo proposto de compreender as inovações empreendidas nos serviços estudados e suas implicações no processo de oferta de valor de cada um deles. Nesse sentido, aspectos sobre a inovação em serviços, os modelos de oferta de valor e o método PCN Analysis são apresentados.

\subsection{Inovação nos Serviços}

A inovação nos serviços é definida de diversas maneiras. Algumas vezes, a inovação é vista como melhorias associadas às ofertas do serviço propriamente 
ditas. Há casos em que a inovação está associada com a melhoria dos processos internos que normalmente resultam no aumento da produtividade e da eficiência da organização. Há também situações em que a inovação está vinculada a melhorias na experiência do cliente ou a mudanças significativas no papel que ele desempenha (ZEITHAML; BITNER; GREMLER, 2014).

A inovação no serviço também pode ser vista como resultado da compreensão sobre os problemas do cliente e as tarefas que eles querem ver realizadas. Nesse contexto, a inovação consiste no desenvolvimento de soluções para ajudá-los a alcançar esses objetivos. Portanto, torna-se primordial descobrir o que os clientes desejam e desenvolver serviços e soluções considerando essa compreensão (BETTENCOURT; ULWICK, 2008; BETTENCOURT, 2010).

A inovação no serviço pode ser obtida por meio de um esforço deliberado da organização no desenvolvimento do sistema de operações de serviços de modo estruturado, delegando-o um corpo de pessoas da organização. Essas atividades fazem parte do projeto de serviço.

O projeto de serviço auxilia no processo de criação de novos serviços ou no de melhoraria dos serviços existentes (MORITZ, 2005). Nessa direção, o projeto de serviço tem como objetivo "[...] assegurar que as interfaces dos serviços sejam úteis, usáveis e desejáveis sob o ponto de vista dos clientes e eficazes, eficientes e distintas sob o ponto de vista do prestador" (MAGER; SUNG, 2011, p. 1). Portanto, o projeto deve ser visto como uma abordagem estratégica que auxilia os provedores de serviços a desenvolverem um posicionamento estratégico claro para suas ofertas de serviços (MAGER; SUNG, 2011; MORITZ, 2005).

Contudo, diferentemente da área de projeto $e$ desenvolvimento de bens, a concepção e o desenvolvimento de serviços é uma área pouco desenvolvida. Isso decorre, em parte, da dificuldade de incorporar a influência do cliente no desenho do serviço. Afinal, na maioria dos serviços, os clientes fornecem recursos físicos ou informativos de qualidade duvidosa e incerta. Portanto, a variabilidade incorporada ao processo de serviço decorrente da participação do cliente contribuiu de modo significativo para uma abordagem pouco estruturada desta área (SAMPSON; CHASE, 2010).

Em um dos primeiros trabalhos sobre o tema, os autores Bitran e Lojo (1993) colocam que desenvolver um sistema de operações de serviço implica na definição de especificações, no planejamento de medidas de desempenho, de infraestrutura, de capacidade de execução, de fluxo e de divisão do trabalho.

Ainda com relação a esse tema, os autores Fitzsimmons e Fitzsimmons (2014) identificaram duas abordagens genéricas para o projeto de um sistema de operações de serviços. A primeira delas é a abordagem de linha de produção. Nessa abordagem, os serviços são planejados de maneira que sejam realizados em um ambiente controlado para garantir consistência em termos de qualidade e eficiência da operação. A outra abordagem consiste no planejamento dos serviços privilegiando a participação ativa dos clientes no processo. Dentro desses dois extremos, várias abordagens intermediárias podem ser definidas.

A literatura de gestão de serviços aponta vários métodos para o desenvolvimento de um sistema de operações de serviços. Muitas deles enfatizam o desenvolvimento do processo, tais como o Fluxograma Tradicional (ou Mapa de Processo), Service Blueprint (SHOSTACK, 1984), Mapa do Serviço (KINGMAN-BRUNDAGE; GEORGE; BOWEN, 1995), IDEFØ (CONGRAN; EPELMAN, 1995) e SERVPRO (SANTOS; VARVAKIS, 2002).

Contudo, cabe ressaltar que um ponto comum à maioria desses métodos é a propensão em restringir o estudo dos processos ao domínio do provedor do serviço. Em outras palavras, as demais entidades envolvidas no serviço são desconsideradas no estudo dos processos. Porém, nenhuma organização de serviço realiza os processos com total independência. Afinal, uma característica de todo serviço é a sua codependência (SAMPSON; CHASE, 2010).

Diante disso, a ferramenta de projeto de serviços utilizada para a visualização dos serviços estudados foi o diagrama PCN, uma vez que ele fornece a base necessária para a "análise de processos de serviços, redes, estratégias, inovações e outras questões gerenciais" (SAMPSON, 2014, p. 21) e auxilia na representação de opções de configurações de processo de uma forma que não foi possível ser realizada com os métodos anteriormente disponibilizados (SAMPSON; CHASE, 2010).

Contudo, antes da apresentação do método PCN Analysis, faz-se necessário apontar as diferentes perspectivas sobre o processo de oferta de valor pelas organizações para o cliente. 


\subsection{As Perspectivas Sobre o Processo de Oferta de Valor}

Ao longo das últimas décadas diversas abordagens surgiram no que se refere ao processo pelo qual as organizações buscam ofertar valor para o cliente (CHRISTOPHER, 2007) e o que se observa é que enquanto as primeiras apoiaram-se na perspectiva de oferta de valor como um processo linear, sequencial, unidirecional, centrado na organização e considerando o cliente como uma variável exógena, as abordagens mais recentes apontam a oferta de valor como um processo não linear, contextual, e no qual o cliente é um participante ativo e que resulta em uma experiência criada em conjunto (fornecedores e clientes) (PRAHALAD; RAMASWAMY, 2004a; VARGO; LUSCH, 2004; VARGO; MAGLIO; AKAKA, 2008).

Cabe destacar, no entanto, que essas diferenças nas perspectivas sobre o processo de oferta de valor encontram subsídios em duas abordagens teóricas distintas. São elas a lógica Produto-Dominante e a lógica Serviço-Dominante. As principais diferenças entre estas abordagens no que se refere ao processo de oferta de valor são apontadas no Quadro 1.

\begin{tabular}{|c|c|}
\hline $\begin{array}{l}\text { Lógica Produto-Dominante } \\
\text { (VISÃo INDUSTRIAL) }\end{array}$ & Lógica SeRviço-Dominante \\
\hline $\begin{array}{l}\text { Criação de valor é sequencial, } \\
\text { unidirecionalmente } \\
\text { transitiva, melhor descrita } \\
\text { por "cadeias de valor". }\end{array}$ & $\begin{array}{l}\text { Criação de valor é sincrônica, } \\
\text { interativa, melhor descrita } \\
\text { por "constelações de valor". }\end{array}$ \\
\hline $\begin{array}{l}\text { Todo valor gerado pode ser } \\
\text { medido em termos monetários. }\end{array}$ & $\begin{array}{l}\text { Alguns valores gerados não } \\
\text { podem ser quantificados ou } \\
\text { medidos monetariamente. }\end{array}$ \\
\hline Valor é adicionado. & $\begin{array}{l}\text { Os valores são coinventados, } \\
\text { combinados e reconciliados. }\end{array}$ \\
\hline $\begin{array}{l}\text { Valores são "objetivos" (troca) } \\
\text { e "subjetivos" (utilidade). }\end{array}$ & $\begin{array}{l}\text { Valores são "contingentes" } \\
e \text { "atuais" (estabelecido } \\
\text { de forma interativa). }\end{array}$ \\
\hline $\begin{array}{l}\text { Valor "percebido" na } \\
\text { transação apenas para o } \\
\text { fornecedor (evento). }\end{array}$ & $\begin{array}{l}\text { Valor é coproduzido, com o } \\
\text { cliente, todo o tempo, para } \\
\text { ambos os coprodutores } \\
\text { (relacionamento). }\end{array}$ \\
\hline $\begin{array}{l}\text { Organização e atividade são } \\
\text { as unidades de análise. }\end{array}$ & $\begin{array}{l}\text { Interações (ofertas) são } \\
\text { as unidades de análise }\end{array}$ \\
\hline
\end{tabular}

Quadro 1: Duas perspectivas para o processo de oferta de valor Fonte: Adaptado de Ramírez (1999)

A partir do exposto no Quadro1, pode-se depreender que enquanto na lógica Produto-Dominante a oferta de valor é produzida e o valor é definido pela organização, na Lógica Serviço-Dominante, a oferta de valor passa a ser o resultado das interações entre a organização e os seus clientes e o valor passa a ser definido pelo cliente a partir do valor em uso.

Nesse sentido, Grönroos e Voima (2013, p. 135) complementam apontando que:

Quando o valor é percebido como valor em uso para o cliente, o foco não é mais predominantemente num pacote personalizado de produtos ou serviços trocados por um preço. Em vez disso, a criação de valor torna-se um processo contínuo, que enfatiza as experiências, a lógica e a capacidade do cliente para extrair valor além dos produtos e dos outros recursos utilizados (criar valor em uso).

Portanto, na lógica Serviço-Dominante, a organização sozinha não é capaz de criar valor, ela apenas pode oferecer uma proposta de valor, a qual será totalmente ou parcialmente aceita pelo cliente (LUSCH; VARGO; WESSELS, 2008) e o valor passa a ser entendido como "[...] um processo físico, virtual, mental ou de aquisição que é criado pelo cliente (individualmente e socialmente), durante o uso de recursos existentes nos processos e por seus resultados." (GRÖNROOS; VOIMA, 2013, p. 144).

Diante desse contexto, três fatores devem ser considerados. São eles: os clientes participam no processo de serviço, sendo os elementos centrais; o produto tangível é o um dos meios utilizados para a entrega do valor, não é mais o foco central de sua construção; e o valor é circunstancial, ou seja, é determinado pelo cliente de acordo com seu uso (Lusch et al., 2008).

Posto isso, para exemplificar tal mudança na perspectiva do processo de oferta de valor pela organização para o cliente, faz-se necessário apresentar as características de três modelos de oferta de valor. São eles: o modelo de criação de valor, o modelo de coprodução de valor e modelo de cocriação de valor.

O modelo de criação de valor (ou de cadeia de valores) pressupõe que a oferta de valor é um processo resultante de atividades conduzidas internamente pela organização e pelas organizações envolvidas em sua cadeia produtiva e se baseia no conceito de valor como "[...] o montante que os compradores estão dispostos a pagar por aquilo que uma organização lhes fornece" (PORTER, 1998, p. 34). 
O modelo de coprodução de valor possui como características o cliente ser percebido como um recurso ao fornecer informações que servem de inputs para a prestação do serviço pelo provedor e participar, principalmente, no final do processo de serviço (CHATHOTH et al., 2013). Além disso, a interação com o cliente é esporádica e ocorre no sentido de ouvir o cliente (BALLANTYNE; VAREY, 2006).

No modelo de cocriação de valor, por sua vez, o cliente é um elemento ativo que participa em todas as etapas do processo de serviço e para que o valor possa ser realizado (aceito e criado) pelo cliente, faz-se essencial o engajamento e a ocorrência de uma experiência significativa para o mesmo (Chathoth et al., 2013).
Complementando, Prahalad e Ramaswamy (2004b) argumentam que para a adoção do modelo de cocriação de valor elementos como o diálogo, a experiência desejada pelo cliente, a avaliação do risco e a simetria de informações devem ser considerados. Já Ballantyne e Varey (2006) argumentam que o relacionamento decorrente das interações, o diálogo entre os envolvidos no serviço e o compartilhamento de informações são atividades facilitadoras do processo de cocriação de valor.

Realizadas essas considerações, no Quadro 2 apresenta-se um resumo do exposto sobre os modelos de oferta de valor.

\begin{tabular}{|c|c|c|c|}
\hline & Criação de valor & Coprodução de valor & Cocriação de valor \\
\hline $\begin{array}{l}\text { Papel do Cliente } \\
\text { (CHATHOTH et al., 2013) }\end{array}$ & $\begin{array}{l}\text { Passivo (receptor } \\
\text { do serviço). }\end{array}$ & $\begin{array}{l}\text { Passivo (percebido } \\
\text { como um recurso). }\end{array}$ & $\begin{array}{l}\text { Ativo (fornecedor de } \\
\text { informação / criador de valor). }\end{array}$ \\
\hline $\begin{array}{l}\text { Participação do cliente no serviço } \\
\text { (CHATHOTH et al., 2013) }\end{array}$ & $\begin{array}{l}\text { Inexistente (receptor } \\
\text { do serviço). }\end{array}$ & $\begin{array}{l}\text { Participa principalmente } \\
\text { no final do processo. } \\
\text { Fornece informações. }\end{array}$ & $\begin{array}{l}\text { Participa de todas as } \\
\text { etapas do processo. } \\
\text { Fornece informações }\end{array}$ \\
\hline $\begin{array}{l}\text { Produção do serviço } \\
\text { (CHATHOTH et al., 2013) }\end{array}$ & Centrada na empresa. & Centrada na empresa. & Centrada no cliente. \\
\hline $\begin{array}{l}\text { Interação comunicativa } \\
\text { (BALLANTYNE; VAREY, 2006; } \\
\text { CHATHOTH et al., 2013; } \\
\text { PRAHALAD; RAMASWAMY, 2004b) }\end{array}$ & Informativa. Inexistente. & $\begin{array}{l}\text { Comunicacional. } \\
\text { Ouvir os clientes. }\end{array}$ & $\begin{array}{l}\text { Dialógica } \\
\text { Dialogar com os clientes. }\end{array}$ \\
\hline $\begin{array}{l}\text { Interação com os clientes } \\
\text { (BALLANTYNE; VAREY, 2006) }\end{array}$ & Inexistente. & Esporádicas. & Frequentes. \\
\hline $\begin{array}{l}\text { Transparência } \\
\text { (PRAHALAD; RAMASWAMY, 2004b) }\end{array}$ & Não transparente. & Pouco transparente. & Transparente. \\
\hline $\begin{array}{l}\text { Conhecimento } \\
\text { (BALLANTYNE; VAREY, 2006) }\end{array}$ & Não Compartilhado. & Pouco Compartilhado. & Compartilhado e aplicado. \\
\hline
\end{tabular}

Quadro 2: Síntese das características dos modelos de oferta de valor

Fonte: Elaborado pelos autores deste artigo com base na revisão da literatura

Posto isso, na próxima seção será apresentado o Método PCN Analysis.

\subsection{O Método PCN Analysis}

De acordo com Sampson (2014, p. ix), o propósito do método PCN Analysis é "[...] melhorar o processo de negócio do serviço por meio da sistemática documentação dos processos, avaliação do valor proveniente dos seus componentes, identificação das áreas com problemas e geração sistemática de alternativas para a melhoria de processos".
Para isso, a análise começa pela documentação de um processo de serviço interativo e inclui a identificação dos seguintes elementos:

\footnotetext{
- valor para o cliente;

- custos para o cliente (custos psicológicos de esforço, espera e etc.);

- custos para o provedor (trabalho e outros recursos);

- potencial de receita para o provedor;

- risco de falhas no processo incluindo a identificação de potenciais causas de falhas nos processos. (SAMPSON, 2014, p. ix)
} 
Para o mapeamento do processo no método PCN Analysis utiliza-se o diagrama PCN. O diagrama PCN foi elaborado "[...] a partir dos pontos fortes de outras técnicas de fluxogramas, sublinhando ao mesmo tempo as condições e oportunidades únicas de desenho para processos de serviços interativos [...]" (SAMPSON, 2014, p. 19) e possibilita uma visão equilibrada das interações entre as entidades envolvidas no processo de serviço (KAZEMZADEH; MILTON; JOHNSON, 2015; ULLAH, 2014).

Quando utilizado em nível estratégico, o diagrama PCN apresenta uma nova perspectiva para a atuação dos clientes nos processos e, portanto, possibilita novas formas de atuação para a organização. Isto decorre da concepção de que, em processos interativos, mais do que uma parte externa à empresa, o consumidor é parte integrante do processo produtivo (SAMPSON, 2014).

Por sua vez, quando utilizado em nível operacional, o método facilita o entendimento e visualização do processo, possibilitando a integração eficiente do mesmo, pois representa o processo tanto nas regiões de interação, seja esta direta ou por meio de substituto de interação, quanto na região de processamento independente de cada domínio além dos recursos envolvidos (SAMPSON, 2014).

A Figura 1 apresenta os elementos principais e os princípios envolvidos na elaboração de um diagrama PCN.

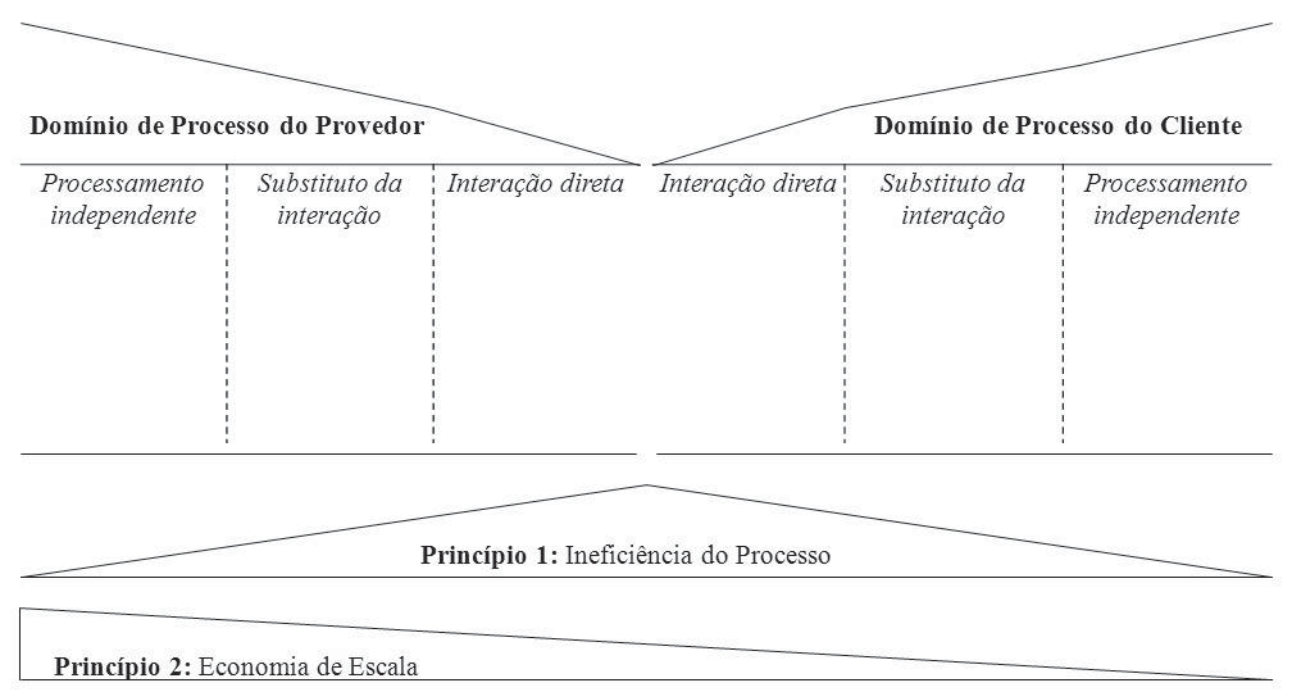

Princípio 3: Customização

Figura 1: Elementos componentes do diagrama PCN

Fonte: Adaptada de Sampson (2014)

Como pode ser observado, cada entidade envolvida no processo possui uma área de domínio. Um domínio de processo refere-se à sequência de passos que é iniciada, liderada, executada ou, em algum nível, controlada por uma entidade envolvida no processo (SAMPSON, 2012; 2014).

Cada domínio de processo, por sua vez, possui três regiões. São elas: região de interação direta, região de interação substituta e região de processamento independente. A região de interação direta abrange etapas que envolvem a interação entre as pessoas das duas entidades analisadas no processo. A região de interação substituta abarca as etapas que envolvem interação com os pertences, informações ou tecnologia de outra entidade do processo, mas sem a ocorrência de interações entre as pessoas das duas entidades. A região de processamento independente compreende as etapas que atuam sobre os recursos que pertencem 
e são controlados por uma entidade, sem que ocorra qualquer interação com outras entidades (SAMPSON, 2012, 2014; SAMPSON, CHASE, 2010).

Diante disso, o entendimento da importância dessas regiões no projeto do serviço faz-se essencial, uma vez que o posicionamento do processo em cada uma destas regiões interfere no modelo de oferta de valor, o qual resultará no potencial valor proposto $e$, consequentemente, na realização de valor por parte do cliente (SAMPSON, 2014). Ademais, por meio do posicionamento das atividades nas diversas regiões de domínio, o projeto de serviço pode adaptar os processos às preferências do cliente e/ou aumentar a economia de escala dos mesmos (KAZEMZADEH; MILTON; JOHNSON, 2015).

Contudo, esse posicionamento é balizado por quatro princípios, são eles: Princípio 1 - Ineficiência do Processo; Princípio 2 - Economia de Escala; Princípio 3 - Customização; e Princípio 4 - Substituto da Interação.

A Ineficiência do Processo, Princípio 1, aponta que "[...] de um modo geral, o processamento interativo é menos eficiente do que o processamento independente, com processos diretamente interativos sendo os menos eficientes" (SAMPSON, 2014, p. 48). Esse princípio encontra subsídios na argumentação de Chase (1978) sobre o impacto negativo da presença do cliente nas operações. Contudo, deve-se considerar que a lógica de análise realizada por Chase (1978) estava calcada na lógica Produto-Dominante na qual a eficiência operacional era alcançada por meio da racionalização dos processos e pela diminuição da interferência dos clientes no processo.

Ainda de acordo com o Princípio 1, a região de interação substituta tem um potencial maior de eficiência operacional que a região de interação direta. Quando ocorre no domínio de processo do cliente, isso decorre do fato de a empresa poder limitar e controlar a gama de insumos fornecidos pelo cliente $e$ por deixar o cliente executar a ação, reduzindo assim a carga de processamento sobre a empresa. Quando ocorre no domínio de processo do provedor, o mesmo tem maior controle sobre o processo pela redução na variabilidade decorrente da diminuição da interferência do cliente no processo (SAMPSON, 2014; SAMPSON; CHASE, 2010).

A Economia de Escala, Princípio 2, explicita que "[...] custos fixos elevados favorecem o processamen- to por provedor especializado, o qual pode espalhar esses custos fixos em mais unidades produzidas" (SAMPSON, 2014, p. 48). Em outras palavras, quanto mais atividades estiverem na região de processamento independente no domínio de processo do provedor, maior será a eficiência operacional da organização, pois a produção não sofrerá as alterações inerentes da variabilidade introduzida pelos clientes nos processos.

Contudo, é importante ressaltar que a redução ou a acomodação da participação do cliente não são as únicas maneiras de se alcançar a eficiência operacional em serviços. De acordo com Frei (2006), o gerenciamento da interferência do cliente nos processos de serviço pode assegurar que a variabilidade oriunda da participação deles não onere os custos operacionais da organização.

Nessa perspectiva, Frei (2006) aponta duas alternativas para o planejamento da interferência do cliente nos processos de serviços. A primeira alternativa decorre da segmentação dos clientes com base no tipo de variabilidade que introduzem (redução descompromissada). Já, a segunda alternativa refere-se à possibilidade de grande parte do trabalho ser realizada por trabalhadores de baixo custo ou pelos próprios clientes (acomodação de baixo custo).

A Customização, Princípio 3, aponta que a “[...] personalização do serviço aumenta com o deslocamento das etapas do processo na direção da região de processamento independente do domínio do cliente [...]" (SAMPSON, 2014, p. 48), ou seja, um maior grau de personalização do serviço pode ser alcançado ao possibilitar ao cliente a condução independente do processo (SAMPSON; CHASE, 2010).

Nesse sentido, o maior poder de decisão sobre o produto final $e$ a maior atuação do cliente no processo do serviço ao assumir o papel de coprodutor do serviço possibilitarão não somente maior eficiência, mas também gerará maior eficácia no processo. Porém, para que isto ocorra efetivamente, deve-se assegurar que o cliente tenha as habilidades e os recursos necessários para o desenvolvimento de suas novas tarefas (SAMPSON, 2014; TORRES JUNIOR; MIYAKE, 2011).

Por fim, o Posicionamento Substituto, Princípio 4, reforça a questão da existência de outras formas de alcance de eficiência que não seja pela redução da participação do cliente no processo de serviço. Além disto, proporciona a melhoria na customização 
(Princípio 3) enquanto reduz os custos (Princípio 1) e, portanto, pode ser uma opção para equilibrar eficiência e eficácia em serviços. Retomando os apontamentos de Frei (2006), esta seria a alternativa de gerenciamento da interferência da participação do cliente denominada "acomodação de baixo custo".

Posto isso, em relação à decisão sobre qual seria o posicionamento ótimo de um processo nas regiões de domínio, Sampson (2014, p. 49) aponta que esse posicionamento

[...] depende do que o provedor está tentando realizar em uma particular oferta para um determinado segmento de clientes (ex.: um grupo de clientes com necessidades e potencialidade similares para satisfazer essas necessidades). Este posicionamento do processo é uma decisão estratégica na qual se define o que o negócio da organização é em termos de proposição de valor e suas competências requeridas. $\mathrm{O}$ posicionamento do processo também define o relacionamento com cliente no que ser refere aos papéis que deverão ser assumidos pelo provedor e vis a vis os papéis requeridos do cliente.

Diante do exposto, pode-se perceber que a escolha do posicionamento de um processo em uma determinada região de domínio explicitará a opção da empresa pelo modo de eficiência a ser alcançado e pelo modelo de oferta de valor adotado pelo serviço.

Ainda no que se refere ao modelo de oferta de valor, a opção por posicionar os processos na região de processo independente do domínio do provedor indicam a adoção pela organização do modelo de criação de valor, ou seja, o provedor oferta o serviço como um "pacote fechado" e o cliente tem um papel passivo no processo. Na região de interação direta entre os domínios do provedor e do cliente, há a participação do cliente no processo como fornecedor de inputs e, portanto, o modelo adotado é o da coprodução de valor. Já, na região de processo independente do domínio do cliente o modelo adotado é o da cocriação de valor, pois o cliente assume um papel ativo no processo e realiza o valor para si mesmo por meio de experiências exclusivas (SAMPSON, 2014).

Diante das diferentes possibilidades de proposta de valor oriundas do posicionamento do processo em cada região, pode-se depreender que diferentes requisitos de gestão serão demandados. A Figura 2 aponta as principais características dos processos que ocorrem em cada região.

\begin{tabular}{|c|c|c|c|c|}
\hline \multicolumn{2}{|c|}{$\begin{array}{l}\text { Domínio de Processo do Provedo } \\
\text { Beneficiário genérico }\end{array}$} & & \multicolumn{2}{|c|}{$\begin{array}{c}\text { Domínio de Processo do Cliente } \\
\text { Beneficiário específico } \\
\end{array}$} \\
\hline $\begin{array}{l}\text { Processamento } \\
\text { independente }\end{array}$ & $\begin{array}{l}\text { Substituto da } \\
\text { interação }\end{array}$ & Interação direta Interação direta & $\begin{array}{l}\text { Substituto da } \\
\text { interação }\end{array}$ & $\begin{array}{l}\text { Processamento } \\
\text { independente }\end{array}$ \\
\hline \multirow[t]{2}{*}{$\begin{array}{l}\text { Região 1: } \\
\text { Caracterizada } \\
\text { por eficiência e } \\
\text { cumprimento de } \\
\text { tarefas em } \\
\text { conformidade } \\
\text { com } \\
\text { especificações } \\
\text { pré-definidas }\end{array}$} & $\begin{array}{l}\text { Região 2: } \\
\text { Caracterizada } \\
\text { pela rápidae } \\
\text { precisa } \\
\text { respostaaos } \\
\text { requisitos dos } \\
\text { clientes }\end{array}$ & $\begin{array}{l}\text { Região 3: } \\
\text { Caracterizada pela empática } \\
\text { compreensão e adaptação às } \\
\text { necessidades do cliente. }\end{array}$ & $\begin{array}{l}\text { Região 4: } \\
\text { Caracterizada } \\
\text { pela robustez } \\
\text { e clara } \\
\text { disseminação } \\
\text { dos papéis do } \\
\text { cliente. }\end{array}$ & $\begin{array}{l}\text { Região 5: } \\
\text { Caracterizada } \\
\text { pela efetiva } \\
\text { correspondên } \\
\text { cia entre } \\
\text { capacidades } \\
\text { dos clientes e } \\
\text { característica }\end{array}$ \\
\hline & & Intensidade do consumidor & & \\
\hline
\end{tabular}

Figura 2: As diferentes regiões em um diagrama PCN

Fonte: Adaptada de Sampson (2014) 
Nesse sentido, por exemplo, processos posicionados na Região 1 apresentam a possibilidade de trabalharem com procedimentos operacionais padrões. Já, na Região 3, há necessidade de um maior grau de seleção e treinamento dos empregados para que os requisitos do consumidor possam ser respondidos por processos que estejam dentro das capacidades do provedor. E, na Região 5, o papel principal do provedor é fornecer recursos necessários para que o consumidor possa conduzir o processo (SAMPSON, 2014).

Contudo, posicionar os processos na Região 4 ou na Região 5 demanda do cliente uma maior participação no processo. Portanto, deve-se considerar a necessidade de anuência do cliente na assimilação de novos procedimentos e do novo papel que deverá desempenhar. Diante disso, "[...] a organização deve se antecipar e selecionar ações que efetivamente possam aumentar as chances de obter uma maior cooperação de seus clientes" (TORRES JUNIOR; MIYAKE, 2011, p. 188).

Além desses princípios, para a análise das alternativas de inovação nos serviços, Sampson (2014) baseado no trabalho de Normann ( 2001), classifica as inovações em dois tipos: inovação de "ativação" ou inovação de "alívio".

a) Inovação de "ativação" (enabling): refere-se à inovação que reposiciona etapas do processo na direção do domínio de processo do cliente, o que permite que o mesmo assuma a responsabilidade pela condução de partes do processo sem, entretanto, diminuir a proposta de valor ofertada e ainda aumentando a eficiência e a personalização do serviço (SAMPSON, 2014).

b) Inovação de "alívio" (relieving): refere-se à inovação que reposiciona etapas do processo na direção do domínio de processo do provedor. Esta inovação possibilita não somente a redução do esforço necessário por parte do cliente, mas também o aumento da qualidade e confiança nos resultados, especialmente quando a etapa requer habilidades altamente especializadas, uma vez que proporciona maior controle por parte do provedor (SAMPSON, 2014).

Normann (2001, p. 36, grifo nosso) aponta as razões para a escolha de cada uma destas inovações, ou seja:
Se alívio, significa "eu posso fazer isso por você uma vez que eu sou mais especializado e posso fazê-lo melhor", ativação significa "eu posso ajudá-lo a fazer, por si mesmo, coisas que você nunca foi capaz de fazer antes, capacitando-lhe com mais habilidades e com recursos que você não tinha acesso".

O autor ainda aponta que a novidade nesta abordagem não reside na atribuição de determinadas atividades para o cliente. Ela está na forma como os conjuntos das atividades totais são desagregados $e$ realocados para diferentes atores, uma vez que não são apenas as atividades finais de criação de valor que são atribuídas aos clientes (NORMANN, 2001).

Além do exposto, destaca-se que a escolha pelo tipo de inovação deverá considerar a compreensão das implicações no custo do serviço e na proposta de valor ofertada pelo mesmo (SAMPSON, 2014), ou seja, deverá também considerar o clássico trade-off entre eficiência (Princípio 2) e eficácia (Princípio 3) no serviço.

Por fim, cabe ressaltar as seguintes características na representação dos processos pelo diagrama PCN. Somente as atividades principais do processo devem ser representadas. As setas indicam, através das conexões apontadas por elas, a sequência da cadeia de processos e, também, um estado de dependência, mostrando que um passo do processo depende de um recurso a ser provido por outro passo do processo. As caixas de bordas arredondadas designam processos que dependem da expertise e do julgamento de determinada entidade. Já, os triângulos invertidos apontam processos de espera (SAMPSON, 2014).

Posto isso, na próxima seção serão apresentados o método e as técnicas de pesquisa utilizadas no estudo.

\section{Métodos e Técnicas de Pesquisa}

Para atingir o objetivo proposto nesta pesquisa, de analisar, por meio da aplicação do método PCN Analysis (Process-Chain-Network Analysis), três serviços de atendimento ao cidadão, ofertados pela Polícia Militar de Minas Gerais, de modo a compreender as inovações empreendidas nos seus sistemas de operações e suas implicações no processo de oferta de valor, a questão que norteou o trabalho foi: Qual é o 
tipo de inovação e consequente modelo de oferta de valor adotado nos serviços de atendimento ao cidadão ofertados pela Polícia Militar de Minas Gerais?

Diante disso, optou-se por um estudo descritivo, com abordagem qualitativa e desenvolvido por meio de um estudo de múltiplos casos.

De acordo com Gil (1999), estudos descritivos têm como principal objetivo a descrição das características de determinada população ou fenômeno ou o estabelecimento de relações entre variáveis. Complementando, Salomon (2001) aponta que este tipo de estudo compreende também registro, análise e interpretação na natureza atual ou processo dos fenômenos.

Em relação à estratégia de pesquisa, a opção pela abordagem qualitativa considerou que os métodos de pesquisa qualitativos são indicados quando o interesse é estudar profundamente e de forma contextualizada um fenômeno em organizações (PETTIGREW, 1992) e que propiciam descrições ricas que permitem que sejam identificados achados inesperados e revistos modelos conceituais (MILES; HUBERMAN, 1994).

A abordagem qualitativa foi fundamentada no método de pesquisa de estudo de caso. A opção pelo estudo de caso ocorreu em função de ser um método de pesquisa em ciências sociais que possibilita compreender em profundidade o fenômeno em estudo (YIN, 2005) e ao estudar múltiplos casos, é possível comparar e observar como as diversas variáveis se comportam de acordo com cada sujeito analisado (FLICK, 2009), o que aumenta a validade da pesquisa e permite $\mathrm{O}$ desenvolvimento de um quadro teórico mais rico (BARRATT; CHOI; LI, 2011).

A escolha dos serviços a serem estudados foi intencional, uma vez que foram selecionados serviços que continham os objetos de estudos necessários para o alcance dos objetivos propostos, o que de acordo com Yin (2005) e Eisenhardt (1989), é recomendável neste tipo de estudo.

Ressalta-se, que os serviços foram selecionados a partir do papel assumido pelo cliente no processo de serviço, uma vez que a literatura afirma que este é um dos elementos condicionantes do tipo de inovação proposta e do modelo de oferta de valor adotado pelo serviço.

Determinados os serviços, as técnicas utilizadas na coleta dos dados foram: entrevista, análise documental e observação direta.
Para orientar os esforços de coleta de dados, foram utilizados três protocolos de entrevista. Um protocolo destinado aos militares responsáveis pelos serviços (tenentes e sargentos), outro para os funcionários da empresa terceirizada que atua junto ao Centro Integrado de Comunicações Operacionais (CICOp) e outro para o representante do Clube de Diretores Lojistas de Belo Horizonte (CDL/BH) que participa de um dos serviços. Seguindo indicação de Eisenhardt (1989), os protocolos continham perguntas não estruturadas e estruturadas. As primeiras permitiram aos entrevistados a oportunidade de compartilharem experiências $e$ as segundas possibilitaram esclarecimentos sobre questões específicas não abordadas durante a parte da entrevista não estruturada. Portanto, os protocolos de entrevista foram elaborados a partir dos elementos apresentados na teoria sem, no entanto, deixar de oferecer a flexibilidade necessária para que os entrevistados expressassem suas percepções e novas perguntas pudessem ser realizadas.

As entrevistas ocorreram no período de fevereiro a junho de 2015. Foram realizadas 15 entrevistas envolvendo, no mínimo, três pessoas em cada tipo de serviço estudado. Cada entrevista durou, em média, uma hora. A regra geral utilizada para encerrar a entrevista foi parar quando nenhuma informação nova surgia, de acordo com Eisenhardt (1989), isto marca o ponto de saturação dos dados. Em todos os casos, as entrevistas envolveram pessoas com diferentes funções dentro do serviço e de diferentes níveis hierárquicos. Dependendo da disponibilidade dos participantes, foram realizadas entrevistas por telefone ou pessoalmente. Além disso, os comandantes das companhias que autorizaram a realização da pesquisa em suas unidades receberam o direito de rever as transcrições e garantia do anonimato para o nível que eles desejassem.

Para complementar, a coleta de dados, optou-se pela análise documental e a observação direta. Como fonte documental optou-se por utilizar os manuais operacionais, denominados doutrinários, e as apresentações institucionais da Polícia Militar de Minas Gerais sobre os serviços analisados. Além disto, após cada entrevista foi solicitado ao participante o fornecimento de documentos que reforçassem os pontos discutidos durante a entrevista. A documentação adicional coletada incluiu material de divulgação de alguns dos 
serviços pesquisados, cartilhas com instruções sobre segurança e formulários de termo de adesão ao serviço.

Em relação às observações diretas, as mesmas aconteceram durante os meses de Abril e Maio de 2015, período durante o qual um dos autores deste trabalho acompanhou a prestação dos serviços estudados.

Diante disto, o uso de múltiplas fontes para a obtenção de dados, denominada de triangulação (YIN, 2005), permitiu confrontar os dados obtidos nas entrevistas com os dados obtidos nas demais fontes.

A análise dos dados coletados, conforme sugerido por Eisenhardt (1989) e Miles e Huberman (1994), aconteceu concomitantemente à coleta de dados $e$ consistiu na identificação do tipo de inovação trazida pelo serviço e consequente proposta de valor. Seguindo o procedimento recomendado por Eisenhardt (1989), primeiro foi realizada a análise em cada caso. Uma vez realizadas as análises intracaso, foi realizada a análise intercasos, ou seja, buscou-se comparar as características identificadas em cada serviço com as características identificadas nos demais serviços pesquisados.

Por fim, para a apresentação e discussão dos achados, optou-se pela elaboração de um quadro, o que possibilitou explicitar os diversos aspectos envolvidos na proposta de inovação e proposta de valor decorrentes de cada serviço.

\section{Apresentação e Discussão dos Casos}

Nesta seção serão apresentados os resultados da pesquisa, então, primeiramente buscou-se caracterizar os três serviços estudados para, em seguida, analisá-los e discuti-los a partir do referencial teórico apresentado anteriormente.

\subsection{Caracterização dos Serviços}

Os serviços que serão apresentados refletem a evolução do policiamento militar para atender as demandas e as transformações sociais. Nesse sentido, cabe ressaltar que a estratégia de policiamento reflete a mudança na percepção da Polícia Militar em relação a sua função, o que, por sua vez, requer melhorias na forma de prestação dos seus serviços e impacta nos resultados alcançados.
Posto isso, diante do atual portfólio de serviços ofertados pela Polícia Militar de Minas Gerais, optou-se por estudar os seguintes serviços de atendimento ao cidadão: Disque 190, Projeto Olho Vivo BH e Rede de Comerciantes Protegidos da Savassi.

Ressalta-se que o Disque 190 será utilizado como o serviço base para a análise do tipo de inovação proposta nos outros dois serviços, uma vez que é o mais antigo dos três serviços de atendimento ao cidadão dentre os apresentados.

\subsubsection{Disque 190}

O serviço de Disque 190 corresponde à central de atendimento à população oferecido pelas polícias militares brasileiras. Em Minas Gerais, por meio de telefonemas ao Centro Integrado de Comunicações Operacionais (CICOp), o cidadão informa a ocorrência de crimes e solicita serviços da Polícia Militar (MINAS GERAIS, 2015).

O processo do serviço Disque 190 segue as seguintes etapas: o cidadão telefona para a central de atendimento por meio do número 190 e a chamada é recebida pela equipe de teledigifonista, funcionários civis de uma empresa terceirizada. A teledigifonista, seguindo um padrão operacional de atendimento, coleta as informações necessárias para sua triagem. Caso a veracidade do fato e a gravidade do mesmo sejam identificados pela teledigifonista, abre-se um chamado, o qual é direcionado para a equipe, formada por militares, responsável pelo despacho de viatura. Em seguida, um despachante identifica a companhia responsável pela área em que o evento está localizado e verifica a disponibilidade de viaturas dessa companhia. Se houver viatura em patrulhamento, ela é destinada para atendimento. Caso contrário, o chamado é posto em uma fila de espera, o qual aguardará até que uma viatura seja disponibilizada. Sendo alocada para atender a ocorrência, a viatura é contatada e desloca-se para o local do evento. Após a chegada ao local, os policiais confirmam as informações recebidas $e$ coletam mais informações para poderem realizar os procedimentos cabíveis. Terminado o atendimento, a viatura retorna à sua atividade de patrulhamento (MINAS GERAIS, 2015).

Cabe ressaltar que embora haja um padrão operacional para o atendimento, tanto as teledigifo- 
nistas entrevistadas quanto os militares que atuam no despacho de viatura apontaram que a efetividade na prestação do serviço depende da qualidade das informações que são fornecidas pelo usuário antes e durante o atendimento em si. Os responsáveis pelo serviço entrevistados afirmaram que, de modo geral, as pessoas não são preparadas para observar e/ou anotar elementos que contribuirão efetivamente para uma melhor realização do serviço.

\subsubsection{Projeto Olho Vivo $B H$}

Regulamentado pela Lei Estadual n. 15.435, de 12 de janeiro de 2005, o Sistema de Patrulhamento Vídeo Monitorado (SPVM), conhecido comumente como "Projeto Olho Vivo BH", iniciou oficialmente suas atividades no dia 13 de dezembro de 2004, com objetivo de promover o apoio às ações e operações da PMMG, bem como aos demais órgãos do Sistema de Defesa Civil, na prevenção e combate da criminalidade na região conhecida como hipercentro ${ }^{1}$ da cidade de Belo Horizonte (MILANI; JESUS, 2012).

Inicialmente foram instaladas 72 câmeras de vídeo-vigilância capazes de possibilitar o monitoramento ininterrupto das regiões do Barro Preto, Savassi e Hipercentro, com o intuito de garantir a ordem pública. Em 2007, mais 72 câmeras foram instaladas em outras regiões, abrangendo os seguintes bairros: Caiçara, Padre Eustáquio, Carlos Prates, Coração Eucarístico, Calafate, assim como a Praça da Liberdade (MILANI; JESUS, 2012).

O processo de atendimento do serviço do Programa Olho Vivo BH (Figura 5) segue as seguintes etapas: o monitoramento é realizado 24 horas por dia pelos operadores do "Olho Vivo", funcionários civis de uma empresa terceirizada, e quando são identificadas situações de risco, o supervisor dos operadores que é um militar, aciona a central de despacho de viatura e o despachante aciona a viatura o que se encontrar mais próxima do local do evento. A viatura desloca-se para o atendimento. Durante o atendimento, busca-se o contato com a vítima e a abordagem do cidadão em

1 O hipercentro foi a região escolhida por ser o coração econômico da cidade. Nesta área há grande concentração de lojas comerciais e fluxo elevado de pessoas em função de realização de compras ou locomoção de um ponto a outro da cidade, utilizando os meios de transporte disponíveis no local (ALVES, 2007). conflito com a lei. Finalizado o atendimento, a viatura retorna ao patrulhamento (MINAS GERAIS, 2015).

De acordo com os operadores entrevistados, o serviço prestado depende da habilidade dos mesmos em identificar a situação de risco e, para isto, são treinados, por militares, para identificarem comportamentos e atitudes que sinalizem potenciais vítimas ou possíveis agentes infratores.

\subsubsection{Programa Rede de Comerciantes Protegidos da Savassi}

O programa Rede de Comerciantes Protegidos é um desdobramento do programa Rede de Vizinhos Protegidos. Foi implementado em 22 de outubro de 2014 em um bairro comercial denominado Savassi, a partir de uma parceria entre PMMG e o Clube de Diretores Lojistas de Belo Horizonte (CDL/BH). Atualmente, a Rede de Comerciantes Protegidos da Savassi possui aproximadamente 180 comerciantes cadastrados.

De acordo com os entrevistados, o processo de formação da Rede de Comerciantes Protegidos segue as seguintes etapas. Inicialmente há a catalogação de todos os comerciantes de uma determinada região. Em seguida, os comerciantes são convidados para o programa. Os comerciantes interessados preenchem um formulário junto com um termo de compromisso para realização do seu cadastro junto a Rede de Comerciantes. Realizado o cadastro, o comerciante é adicionado a um grupo no WhatsApp o qual servirá para a troca de informações sobre segurança. Além disto, o comerciante deverá afixar uma placa em seu estabelecimento explicitando sua vinculação à rede. Participam do grupo os comerciantes, policiais militares e representantes da CDL/BH. O representante da CDL/ $\mathrm{BH}$ é o moderador do grupo e o policial militar designado para o monitoramento do grupo é o responsável pelo contado da rede com o atendimento da PMMG.

Além da comunicação pelo WhatsApp, há encontros mensais para discussão sobre os problemas da região atendida pela Rede de Comerciantes e para que a PMMG possa passar orientações e instruções para os comerciantes.

Em relação ao serviço em si, o atendimento por meio do programa Rede de Vizinhos Protegidos ocorre do seguinte modo: os comerciantes informam 
pelo WhatsApp atitudes suspeitas, situações de risco e a ocorrência de algum fato. O militar que monitora as trocas de informação, ao identificar um fato que necessite de atendimento, aciona a central de despacho de viatura e informa, por meio do WhatsApp, o envio da viatura. O despachante aciona a viatura que se encontrar mais próxima do local do evento. Após a chegada ao local, os policiais confirmam as informações recebidas e buscam coletar mais informações para poderem realizar os procedimentos usuais de eventos desta natureza. Terminado o atendimento, a viatura retorna ao patrulhamento.

De acordo com um dos entrevistados, um dos ganhos do programa é que todos os comerciantes passam a cuidar melhor da segurança do seu estabelecimento, além de auxiliarem outros comerciantes neste mesmo fim. A fala a seguir ilustra esta constatação:
Ao fornecer informações sobre atitudes suspeitas ou sobre a ocorrência de algum fato em seu estabelecimento, o comerciante está ajudando a todos os comerciantes da rede ao mesmo tempo em que irá receber a ajuda dos mesmos. Além disto, o contato direto com a Polícia Militar de Minas Gerais proporciona uma maior agilidade no atendimento (Entrevistado).

\subsection{Análise e Discussão dos Serviços}

Nesta subseção, os três serviços serão analisados por meio do método PCN Analysis. Buscou-se com esse método a identificação das diferenças no projeto dos serviços no que se refere ao tipo de inovação $e$ consequente proposta de valor ofertada.

Na Figura 3, apresenta-se o diagrama $P C N$ e a análise do processo de atendimento do Disque 190.

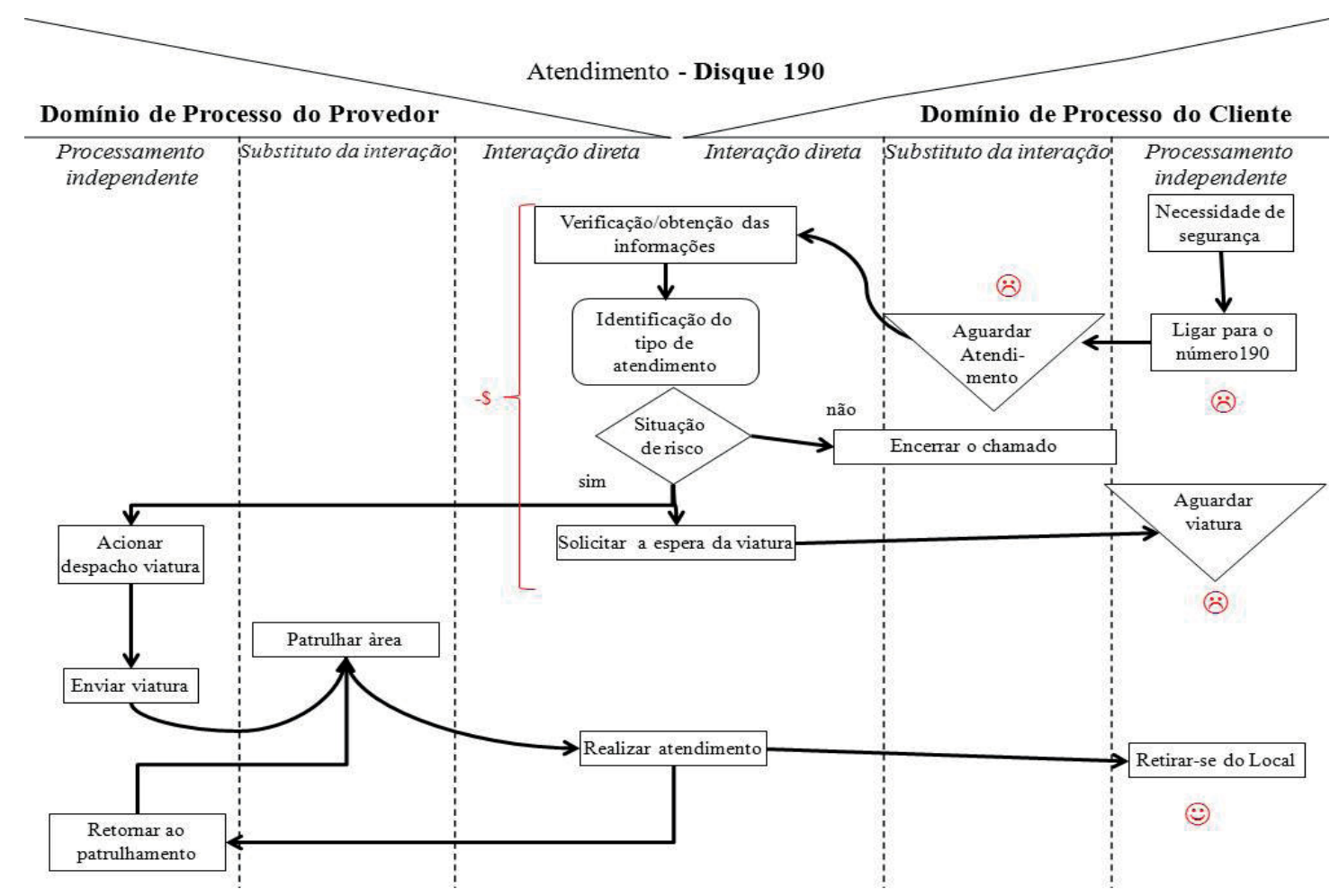

Figura 3: Diagrama PCN e análise do atendimento por meio do Disque 190.

Fonte: Elaborada pelos autores deste artigo com base nos dados da pesquisa

Como pode ser observado na Figura 3, o Disque 190 apresenta um projeto de serviço, que de acordo com o Princípio 1 , do diagrama $P C N$, resulta em mais ineficiência operacional, pois o processo depende de atividades realizadas na região de interação direta. A alta variabilidade oriunda da intensidade do contato com o cliente além de promover a ineficiência do processo, exige alto grau de seleção e treinamento de pessoal para que os requisitos dos cidadãos possam ser atendidos por processos que estejam dentro da capacidade da Polícia Militar de Minas Gerais. Todavia, em termos de eficácia, a proposta do serviço, possibilita a 
participação do cliente e, portanto, a compreensão de suas necessidades e de sua participação no processo, mesmo que seja como recurso, conforme apontado na Figura 2, em relação às características das diferentes regiões do diagrama PCN. Essas constatações confirmam o apontado por Sampson (2014) em relação ao Princípio 1 e às características da região de interação direta.

Todavia, em conformidade com o Princípio 1, para melhorar a eficiência no processo de atendimento do Disque 190, faz-se necessário reduzir as atividades na Região 3, ou seja, na região da interação direta. Para tanto, há a possibilidade de reposicionar os processos afastando-os da região de interação direta tanto para demais áreas do domínio de processo do provedor (Princípio 2), quanto de domínio do cliente (Princípio 3).

Em relação ao modelo de oferta de valor, pode-se depreender que o serviço utiliza as informações do cliente, antes e durante o atendimento. Portanto, caracteriza o modelo de coprodução do valor, uma vez que conforme destacado por Sampson(2014), a Região 3, ou seja, de interação direta, caracteriza este tipo de oferta de valor. Além disto, os achados vão ao encontro do apontado no referencial teórico sobre as características do modelo de coprodução do valor, uma vez que embora haja a necessidade de interação com o cliente, as informações são utilizadas pela PMMG para a prestação do serviço. Portanto, o cliente é percebido como um recurso, o foco do serviço continua sendo a empresa, a comunicação com o cliente ocorre no sentido de ouvir o cliente e de forma esporádica indicando que a informação e o conhecimento são pouco compartilhados.

Como se pode notar, as etapas posicionadas na área de interação direta geram custo financeiro para o provedor (-\$) e geram inconveniências (*), como a espera, para o cliente. Portanto, no projeto dos demais serviços, estas etapas podem ser entendidas como oportunidades de melhorias. Sob esta perspectiva, os serviços Programa Olho Vivo BH e Programa Rede de Comerciantes Protegidos da Savassi, serão analisados como alternativas de reposicionamento das etapas dos processos para a melhoria do serviço de atendimento.

O atendimento por meio do Programa Olho Vivo BH quando comparado ao Disque 190, apresenta a decisão pelo reposicionamento dos processos nas áreas de domínio de processo do provedor, caracterizando uma inovação de "alívio" (relieving), uma vez que transfere etapas do processo para o domínio do provedor (Figura 4).

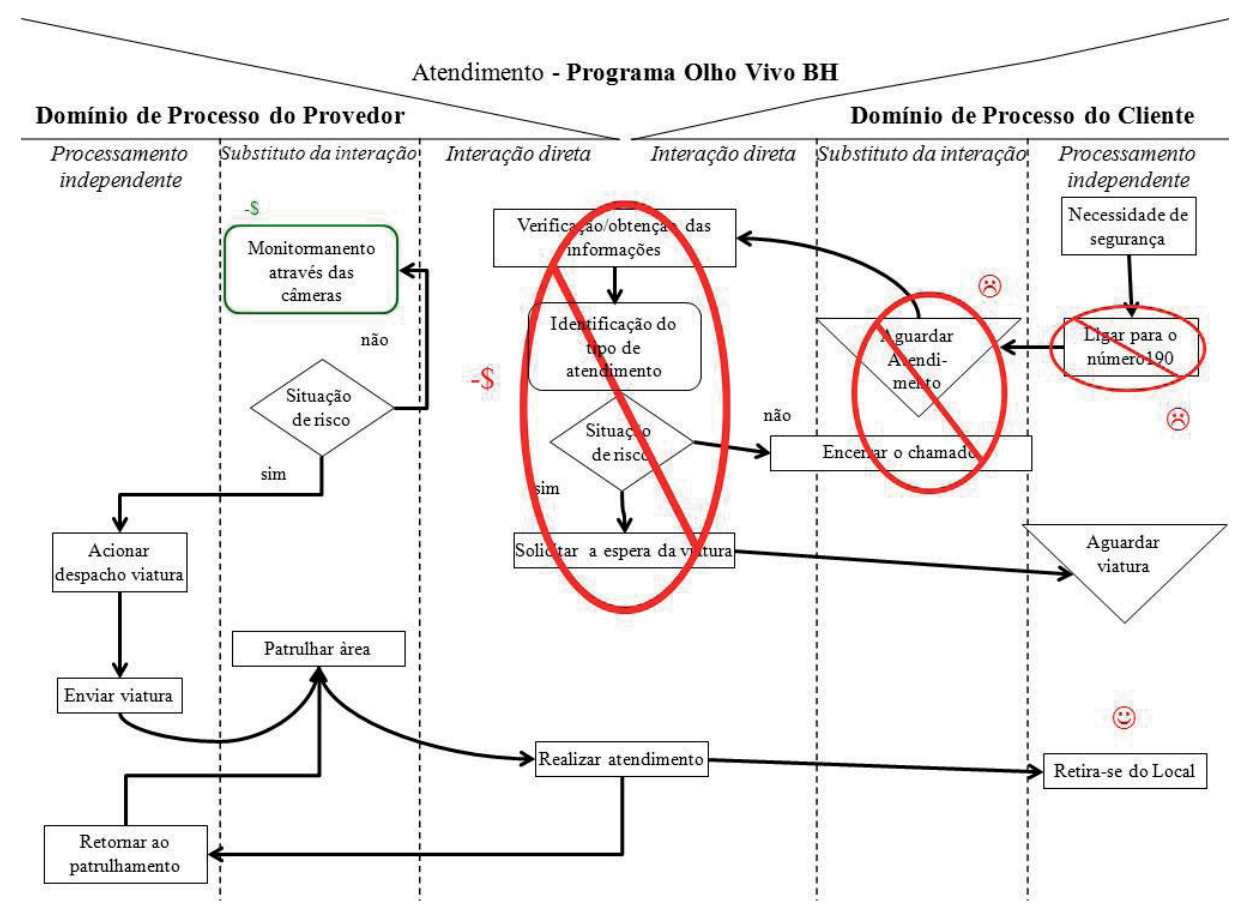

Figura 4: Diagrama PCN e análise do atendimento por meio do Programa Olho Vivo BH

Fonte: Elaborada pelos autores deste artigo com base nos dados da pesquisa 
Como se pode observar, as etapas do processo consideradas como inconvenientes pelo cliente e custos para o provedor foram retiradas desse processo. Portanto, a proposta de melhoria no serviço de atendimento da Polícia Militar de Minas Gerais traz ganhos tanto para o cliente quanto para o provedor.

Em relação à eficiência do processo nas atividades realizadas nas regiões de domínio de processo do provedor, de acordo com o Princípio 2, alcança-se maior economia de escala. Isto decorre não somente do menor grau de contato com o cliente, mas do fato de o processo ser executado por funcionários treinados e de haver maior controle sobre o mesmo por parte do provedor. Isso, corrobora o explicitado no Princípio 1, de que para se alcançar eficiência, aqui compreendida como alto volume de processamento, deve-se deslocar as atividades da região de interação direta em direção à região de processamento independente do domínio do provedor. Além disto, lida com a falta de interação com o cliente utilizando o monitoramento por meio de câmeras de videovigilância como substituto da interação (Princípio 4).

Quanto ao modelo de oferta de valor, pode-se depreender que o serviço Olho Vivo BH adota o modelo de criação de valor. Isso decorre do fato de que grande parte das atividades ocorre nas Regiões 1 e 2, o que revela que o provedor buscar entregar um "pacote fechado" de serviço para o cliente com uma proposta de valor definida, conforme apontamentos de Sampson (2014) . Isso pode ser depreendido também pelo papel passivo do cliente no serviço, uma vez que há baixo (ou nenhum) contato com o cliente. Cabe ressaltar que, de acordo com o referencial teórico apresentado, todas estas características estão presentes no modelo de criação de valor.

Por sua vez, o atendimento por meio do Programa Rede de Comerciantes Protegidos da Savassi quando comparado ao serviço de atendimento do Disque 190 é uma inovação de "ativação", uma vez que se observa o deslocamento de parte das atividades do processo para a região de domínio de processos do cliente (ver Figura 5).

Além disso, pode-se notar na Figura 5 que as etapas do processo consideradas como inconvenientes pelo cliente e os custos para o provedor foram substituídas por etapas que geram benefício (:) para o cliente e maior controle para o provedor do serviço (região de substituto de interação). Portanto, a proposta do Programa Rede de Comerciantes Protegidos da Savassi proporciona melhoria no serviço de atendimento da Polícia Militar de Minas Gerais ao também trazer ganhos tanto para o cliente quanto para o provedor.

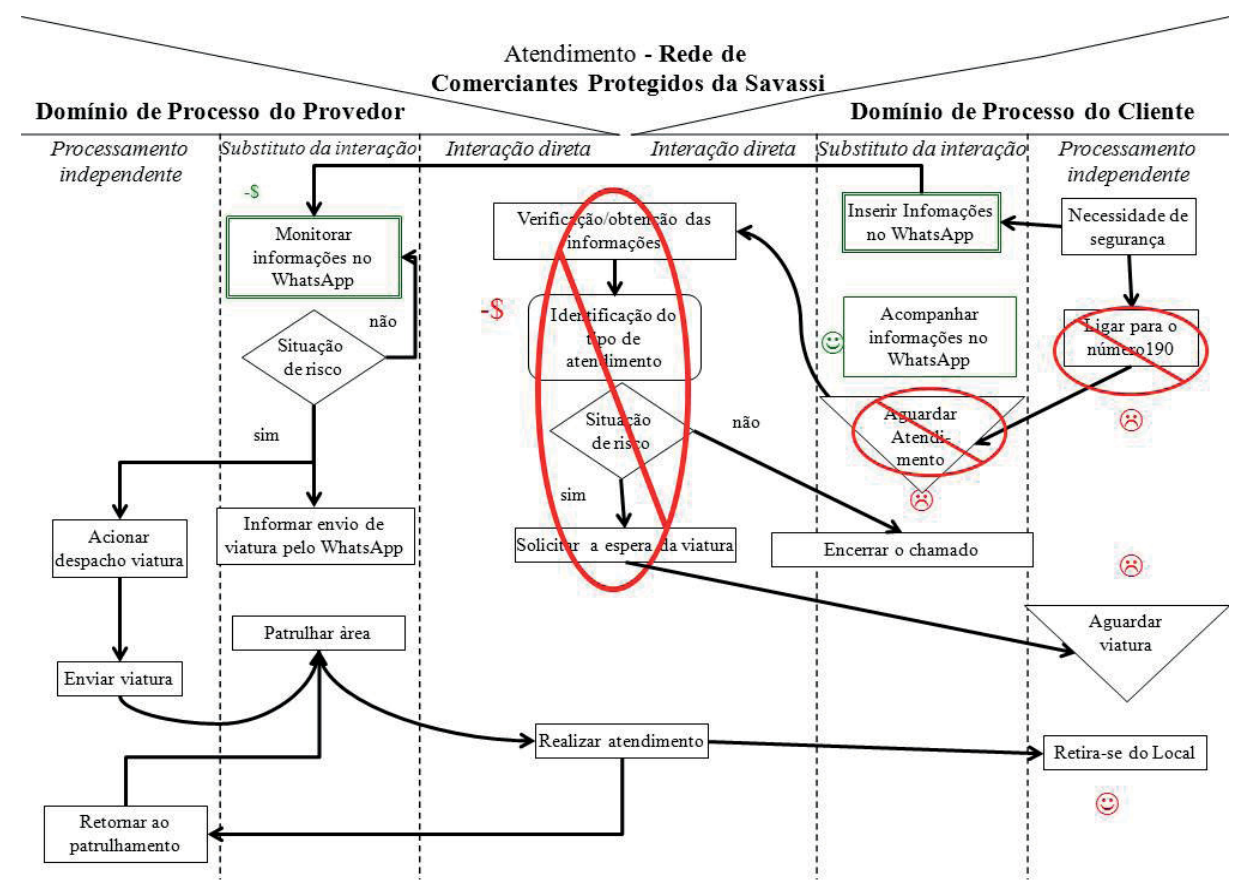

Figura 5: Diagrama PCN e análise do atendimento por meio do Programa Rede de Comerciantes Protegidos da Savassi Fonte: Elaborada pelos autores deste artigo com base nos dados da pesquisa 
Quanto à eficiência, esta é aumentada, pois etapas do processo são afastadas da região de interação direta (Princípio 1). Além disso, a proposta proporciona maior eficácia, ao mover etapas do processo para a região de processos de domínio do cliente aumentando assim a oportunidade de customização do serviço (Princípio 3).

Aqui, cabe ressaltar que, conforme apontado anteriormente sobre a necessidade de preparação do cliente para assumir uma maior participação no processo, a Polícia Militar de Minas Gerais realiza encontros periódicos com os clientes no intuito de prepará-los para esta maior participação no serviço.

Em relação ao modelo de oferta de valor, pode-se depreender que o modelo adotado pelo serviço
Rede de Comerciantes Protegidos da Savassi é o de cocriação de valor, pois, o cliente assume um papel ativo durante o processo e realiza o valor para si, por meio de experiências personalizadas. Além disso, conforme apontado na descrição do serviço, o mesmo favorece uma maior interação entre a Polícia Militar e os clientes, e entre os próprios clientes. Favorecendo também o uso e o compartilhamento do conhecimento entre os clientes. Cabe lembrar que estes elementos são destacados pela literatura como características do modelo de cocriação de valor.

A partir do exposto, o Quadro 3, apresenta uma comparação dos três serviços.

\begin{tabular}{|c|c|c|c|c|}
\hline & $\begin{array}{l}\text { PRINCíPIO ABRANGIDO } \\
\text { PELO SERVIÇO }\end{array}$ & $\begin{array}{l}\text { TiPo de INOVAÇÃo APRESENTADA } \\
\text { PELO SERVIÇO }\end{array}$ & $\begin{array}{l}\text { MODELO DE OFERTA } \\
\text { DE VALOR ADOTADO } \\
\text { PELO SERVIÇO }\end{array}$ & $\begin{array}{l}\text { PAPEL DO CLIENTE } \\
\text { NO SERVIÇO }\end{array}$ \\
\hline Disque 190 & $\begin{array}{l}\text { Ineficiência do processo } \\
\text { (Princípio 1), uma vez } \\
\text { que várias etapas do } \\
\text { processo são realizadas na } \\
\text { região de interação direta. }\end{array}$ & & $\begin{array}{c}\text { Coprodução de } \\
\text { valor, uma vez que } \\
\text { há interação com o } \\
\text { cliente e ele participa } \\
\text { de parte do processo. }\end{array}$ & $\begin{array}{l}\text { O cliente é visto } \\
\text { como um recurso. } \\
\text { O cliente fornece } \\
\text { informações } \\
\text { para que o } \\
\text { serviço ocorra. }\end{array}$ \\
\hline Olho Vivo & $\begin{array}{l}\text { Economia de Escala } \\
\text { (Princípio 2), pois, } \\
\text { busca-se um maior } \\
\text { controle do processo } \\
\text { por parte do provedor } \\
\text { ao realizá-los com uma } \\
\text { menor influência da } \\
\text { participação do cliente. }\end{array}$ & $\begin{array}{l}\text { Inovação de "alívio" (relieving), } \\
\text { pois as atividades são alocadas } \\
\text { nas regióes no domínio de } \\
\text { processo do provedor. Isto } \\
\text { possibilita a redução no esforço } \\
\text { do cliente e aumenta a qualidade } \\
\text { e a confiança nos resultados } \\
\text { uma vez que os operadores são } \\
\text { treinados para sua função. }\end{array}$ & $\begin{array}{l}\text { Criação de valor, uma } \\
\text { vez que a participação } \\
\text { do cliente é reduzida, } \\
\text { buscando entregar } \\
\text { o serviço como um } \\
\text { "pacote fechado" } \\
\text { para o cliente. }\end{array}$ & $\begin{array}{l}\text { O cliente é o } \\
\text { receptor do serviço. } \\
\text { O cliente é passivo } \\
\text { no processo } \\
\text { do serviço. }\end{array}$ \\
\hline $\begin{array}{c}\text { Rede de } \\
\text { Comerciantes } \\
\text { Protegidos }\end{array}$ & $\begin{array}{l}\text { Customização (Princípio } \\
\text { 3), pois o cliente passa a } \\
\text { realizar parte do processo } \\
\text { uma vez que as etapas do } \\
\text { processo são deslocadas } \\
\text { para as regiões e } 4 \text { e } 5 \text {. }\end{array}$ & $\begin{array}{l}\text { Inovação de ativação (enabling) - } \\
\text { pois as atividades são deslocadas } \\
\text { para as demais regiões no } \\
\text { domínio de processo do cliente. } \\
\text { Isto propicia o aumento da } \\
\text { eficiência e da personalização do } \\
\text { serviço, uma vez que o cliente } \\
\text { assume a responsabilidade pela } \\
\text { execução de partes do processo. }\end{array}$ & $\begin{array}{c}\text { Cocriação de valor, } \\
\text { uma vez que o cliente } \\
\text { participa ativamente } \\
\text { do serviço e cria valor } \\
\text { para si e para os } \\
\text { demais participantes } \\
\text { do serviço. }\end{array}$ & $\begin{array}{l}\text { O cliente participa } \\
\text { ativamente do } \\
\text { processo de serviço } \\
\text { e influencia no } \\
\text { modo de realização } \\
\text { do mesmo. }\end{array}$ \\
\hline
\end{tabular}

Quadro 3; Comparação dos três serviços à luz dos fundamentos do método Analysis PCN

Fonte: Elaborado pelos autores deste artigo com base nos dados da pesquisa

\section{Considerações Finais}

É certo que inovar em serviços por meio de um projeto adequado possibilita à organização processos eficientes e a entrega de uma proposta adequada de valor para o cliente. Entretanto, a despeito da relevância do projeto para as propostas de inovações em serviços, a literatura aponta a existência de poucas ferramentas que auxiliam neste processo. Principalmente quando se busca a condução do projeto de serviço considerando não somente as etapas intraorganizacionais, mas, sobretudo as interações entre as entidades envolvidas no processo do serviço.

Diante disso, este trabalho teve como objetivo analisar, por meio da aplicação do método PCN Analysis (Process-Chain-Network Analysis), três serviços de 
atendimento ao cidadão, ofertados pela Polícia Militar de Minas Gerais, de modo a compreender as inovações empreendidas nos seus sistemas de operações e suas implicações no processo de oferta de valor dos mesmos. Os achados do estudo apontaram que o método PCN Analysis foi capaz de auxiliar no processo de identificação do tipo de inovação e do modelo de oferta de valor adotados pelos serviços, além de oferecer subsídios para a tomada de decisão relacionada aos redesenhos de serviços.

O Disque 190 é o serviço de central de atendimento à população oferecido pelas polícias militares brasileiras. Ao aplicar o método de PCN Analysis, na identificação das características do projeto deste serviço, pode-se observar que apesar de proporcionar um atendimento que busca compreender as necessidades dos clientes e adequar suas demandas à capacidade de atendimento da instituição, ele é o serviço com maior grau de ineficiência operacional, uma vez que depende do contato direto com o cliente (Região de Interação Direta) e, portanto, trabalha com um alto grau de variabilidade no processo. Além disso, apresentou sacrifícios tanto para o provedor quanto para o cliente que poderiam ser minimizados. Por fim, em relação ao modelo de oferta de valor, constatou-se que o Disque 190 adota o modelo de coprodução de valor uma vez que o cliente é percebido como um recurso, ainda que forneça informações para a produção do serviço, o foco do serviço é a empresa e a comunicação com o cliente é esporádica. O Programa Olho Vivo BH, também é um serviço de atendimento ao cidadão $e$ consiste no monitoramento de determinadas regióes de Belo Horizonte através de câmeras de vigilância. Ao analisar este serviço, por meio do método PCN Analysis, observou-se que ele caracteriza uma inovação do tipo "alívio", pois reduz etapas do processo realizadas pelo cliente. Em termos de ganho de escala, ele é o mais eficiente dos três serviços analisados, tendo-se em vista que ao deslocar as atividades para o domínio de processo do provedor, ele proporciona um maior controle do processo pelo mesmo além de possibilitar a padronização dos processos. Além disso, o modelo de oferta de valor adotado é o de criação de valor, pois o serviço pode ser entendido como um "pacote fechado" com valor definido e entregue pela organização para o cliente, o qual é, simplesmente, o receptor do mesmo.

A Rede de Comerciantes Protegidos da Savassi é outra forma de ofertar o serviço de atendimento ao cliente e consiste em uma das práticas de policiamento comunitário. Este programa tem a proposta de integrar, comerciantes, Polícia Militar e demais atores envolvidos no processo de segurança pública. Ao realizar o PCN Analysis desse serviço, constatou-se que este oferece uma inovação do tipo "ativação", uma vez que habilita os clientes para assumirem o controle de parte das etapas do processo ao deslocar atividades para as áreas de domínio do processo do cliente. Isto permite também maior personalização do serviço, o que resulta não somente em mais eficiência, mas, também em mais eficácia. Além disto, ao tornar os clientes participantes ativos no processo e oportunizar a interação e o compartilhamento de conhecimento entre eles e a Polícia Militar e entre os próprios clientes, este serviço acaba adotando o modelo de cocriação de valor como modelo de oferta de valor.

Cabe ressaltar que, em relação ao desempenho, a Rede de Comerciantes Protegidos vêm se destacando entre os serviços ofertados pela Polícia Militar de Minas Gerais. De acordo com os entrevistados, nas áreas onde o programa foi implementado, houve redução significativa da taxa de criminalidade. Isso reforça o apontado na teoria de que o modelo de cocriação de valor proporciona às organizações a obtenção de maior efetividade na prestação de seus serviços, uma vez que os mesmos passam a ser concebidos para $e$ com seus clientes, gerando experiências personalizadas e a construção conjunta do valor.

Como limitação do estudo, destaca-se o fato do método PCN Analysis ter sido utilizado para avaliação de serviços já implementados e não para a proposição de novos serviços. Contudo, como o objetivo do estudo era compreender as inovações empreendidas nos sistemas de operações de três serviços de atendimento ao cidadão, realizados pela Polícia Militar de Minas Gerais e suas implicações no processo de oferta de valor adotado pelos mesmos, entende-se que este foi alcançado.

Considerando a relevância do tema na área de marketing e operações principalmente, sugere-se que futuras pesquisas busquem utilizar o método PCN Analysis para a proposição de novos processos de serviços para sistemas de serviços que envolvam redes mais complexas. 


\section{RefERÊNCIAS}

ALVES, D. G. Avaliação do impacto produzido pelo sistema de patrulhamento vídeo monitorado na prevenção do delito de roubo a transeunte, e na sensação de segurança no Hipercentro de Belo Horizonte. 2007. 92 f. Trabalho de Conclusão de Curso (Especialização) - Academia de Polícia Militar/Fundação João Pinheiro, Belo Horizonte, 2007.

BALLANTYNE, D.; VAREY, R. J. Creating value-inuse through marketing interaction: the exchange logic of relating, communicating and knowing. Marketing Theory, [S.l.], v. 6, n. 3, p. 335-348, 2006.

BARRATT, M.; CHOI, T. Y.; LI, M. Qualitative case studies in operations management: Trends, research outcomes, and future research implications. Journal of Operations Management, [S.1.], v. 29, n. 4, p. 329-342, 2011.

BETTENCOURT, L. A. Service Innovation: How to go from customer needs to breakthrough services. Boston: McGraw Hill, 2010.

BETTENCOURT, L. A.; ULWICK, A. W. The CustomerCentered Inovtion Map. Harvard Business Review, [S.l.], May, p. 109-115, 2008.

BITRAN, G. R.; LOJO, M. A Framework for analyzing service operations. European Management Journal, [S.l.], v. 11, n. 3, p. 271-282, 1993.

CHASE, R. B. Where does the customer fit in a service operation? Harvard Business Review, [S.1.], v. 56, n. 6, p. 137-142, 1978.

CHATHOTH, P. et al. Co-production versus co-creation: a process based continuum in the hotel service context. International Journal of Hospitality Management, [S.l.], v. 32, n. 1, p. 11-20, 2013.

\section{CHRISTOPHER, M. Logística e gerenciamento da} cadeia de suprimentos - criando redes que agregam valor. 2. ed. São Paulo: Thomson Learning, 2007.

CONGRAN, C.; EPELMAN, M. How to describe your service: an invitation to the structured abalysis and design technique. International Journal of Service Industry Management, [S.l.], v. 6, n. 2, p. 6-23, 1995.
EISENHARDT, K. M. Building theories from case study research. Academy of Management Review, [S.I.], v. 14, n. 4, p. 532-550, 1989.

FITZSIMMONS, J. A.; FITZSIMMONS, M. J.

Administração de serviços: operações, estratégica e tecnologia da informação. 7. ed. Porto Alegre: Bookman, 2014.

FLICK, U. Introdução à pesquisa qualitativa. 3. ed. Porto Alegre: Artmed, 2009.

FREI, F. X. Breaking the trade-off between efficiency and service. Harvard Business Review, [S.1.], v. 84, n. 11, 2006.

GIANNAKIS, M. Conceptualizing and managing service supply chains. The Service Industries Journal, [S.I.], v. 31, n. 11, p. 1.809-1.823, ago. 2011.

GIL, A. C. Métodos e técnicas de pesquisa social. 5. ed. São Paulo: Atlas, 1999.

GRÖNROOS, C. Service logic revisited: who creates value? And who co-creates? European Business Review, [S.l.], v. 20, n. 4, p. 298-314, 2008.

GRÖNROOS, C.; VOIMA, P. Critical service logic: making sense of value creation and co-creation. Journal of the Academy of Marketing Science, [S.1.], v. 41, n. 2, p. 133-150, 2013.

KAZEMZADEH, Y.; MILTON, S. K.; JOHNSON, L. W. A comparison of concepts in service blueprinting and process-chain-network (PCN). International Journal of Business and Management, [S.I.], v. 10, n. 4, p. 13-25, 2015.

KINGMAN-BRUNDAGE, J.; GEORGE, W. R.; BOWEN, D. E. "Service logic": achieving service system integration. International Journal of Service Industry Management, [S.I.], v. 6, n. 4, p. 20-39, 1995.

LUSCH, R. F; VARGO, S. L.; WESSELS, G. Toward a conceptual foundation for service science: contributions from service-dominant logic. IBM Systems Journal, [S.l.], v. 47, n. 1, p. 5-14, 2008.

MAGER, B.; SUNG, T. J. Special issue editorial: Designing for services. International Journal of Design, [S.I.], v. 5, n. 2, p. 1-3, 2011. 
MILANI, W.; JESUS, E. DE. Projeto "Olho Vivo": dispositivo de vigilância no espaço urbano de Belo Horizonte. Iniciacom, [S.l.], v. 4, n. 1, 2012. Disponível em: <http://200.144.189.84/revistas/index.php/iniciacom/ article/view/786/673>. Acesso em: 15 maio 2015.

MILES, M. B.; HUBERMAN, A. M. Qualitative data analysis: an expanded sourcebook. 2. ed. Thousand Oaks: Sage, 1994.

MINAS GERAIS. Polícia Militar. CICOp. Apresentação Institucional Centro Integrado de Comunicações Operacionais - CICOp. Belo Horizonte: PMMG, 2015

MORITZ, S. Service Design. London: Köln International School of Desing, 2005. Disponível em: <http://hci.liacs. nl/files/PracticalAccess2ServiceDesign.pdf > . Acesso em: 13 nov. 2015

NORMANN, R. Reframing business: when the maps changes the landscape. Chichester: John Wiley \& Sons, 2001.

PETTIGREW, A. M. The character and significance of strategy process research. Strategic Management Journal, [S.1.], v. 13, n. S2, p. 5-16, 1992.

PORTER, M. E. Como as forças competitivas moldam a estratégia. In: MONTEGOMERY, C. A.; PORTER, M. (Org.). Estratégia: a busca da vantagem competitiva. Rio de Janeiro: Campus, 1998. p. 11-27.

PRAHALAD, C. K.; RAMASWAMY, V. Co-creation experiences: the next practice in value creation. Journal of Interactive Marketing, [S.I.], v. 18, n. 3, p. 5-14, 2004a.

PRAHALAD, C. K.; RAMASWAMY, V. The future of competition: co-creating unique value with customers. Boston: Harvard Business School Press, 2004b.

RAMÍREZ, R. Value co-production: intellectual origins and implications for practice and research. Strategic Management Journal, [S.I.], v. 20, n. 1, p. 49-65, 1999.

SALOMON, D. V. Como fazer uma monografia. 10. ed São Paulo: Martins Fontes, 2001.

SALVENDY, G.; KARWOWSKI, W. (Org.). Introduction to Service Engineering. Hoboken: John Wiley \& Sons, 2010.
SAMPSON, S. E. Essentials of service design. 3. ed. Utah: Brigham Young University, 2014.

SAMPSON, S. E. Visualizing service operations. Journal of Service Research, [S.I.], v. 15, n. 2, p. 182-198, $1^{\circ}$ maio 2012

SAMPSON, S. E.; CHASE, R. B. The service innovation toolkit. Brigham Young University, US (unpublished), 2010. Disponível em: < http://services.byu.edu/docs/ Sampson_Chase_PCN_v1b_DRAFT.pdf $>$. Acesso em: 15 maio 2015.

SANTOS, L. C.; VARVAKIS, G. SERVPRO: uma técnica para a gestão de operações de serviços. P. Production Journal, [S.I.], v. 12, n. 1, p. 34-45, 2002.

SHOSTACK, L. G. Designing services that deliver. Harvard Business Review, [S.1.], v. 62, n. 1, p. 133-139, 1984.

TORRES JUNIOR, N.; MIYAKE, D. I. Melhoria de desempenho em serviços: alternativas para lidar com o trade-off entre eficiência e eficácia. Produção Online, [S.I.], v. 11, n. 1, p. 162-193, 2011.

\section{ULLAH, K. Adaptable Service-System Design: an} Analysis of Shariah Finance in Pakistan. 2014. 450 f. Tese (Doutorado) - Brunel University, Londres, 2014. Disponível em: <http://bura.brunel.ac.uk/ bitstream/2438/8281/1/FulltextThesis.pdf > . Acesso em: 10 maio 2015 .

VARGO, S. L.; LUSCH, R. F. Evolving to a new dominant Logic for Marketing. Journal of Marketing, [S.I.], v. 68, n. 1, p. 1-17, 2004

VARGO, S. L.; MAGLIO, P. P.; AKAKA, M. A. On value and value co-creation: A service systems and service logic perspective. European Management Journal, [S.I.], v. 26, n. 3, p. 145-152, 2008

YIN, R. K. Estudo de Caso: planejamento e métodos. 3. ed. Porto Alegre: Bookman, 2005.

ZEITHAML, V. A.; BITNER, M. J.; GREMLER, D. D. Marketing de serviços: a empresa com foco no cliente. 6. ed. Porto Alegre: Editora Bookman, 2014. 